\title{
FeAl and Mo-Si-B Intermetallic Coatings Prepared by Thermal Spraying
}

\author{
Terry C. Totemeier, Richard N. Wright, and W. David Swank \\ Idaho National Engineering and Environmental Laboratory, P.O. Box 1625, MS 2218, Idaho Falls, ID 83415 \\ E-mail: totetc@inel.gov; Telephone: (208) 526-3074; Fax: (208) 526-4822
}

\begin{abstract}
FeAl and Mo-Si-B intermetallic coatings for elevated temperature environmental resistance were prepared using high-velocity oxy-fuel (HVOF) and air plasma spray (APS) techniques. For both coating types, the effect of coating parameters (spray particle velocity and temperature) on the microstructure and physical properties of the coatings was assessed. Fe-24Al (wt.\%) coatings were prepared using HVOF thermal spraying at spray particle velocities varying from $540 \mathrm{~m} / \mathrm{s}$ to $700 \mathrm{~m} / \mathrm{s}$. Mo-13.4Si-2.6B coatings were prepared using APS at particle velocities of 180 and $350 \mathrm{~m} / \mathrm{s}$. Residual stresses in the HVOF FeAl coatings were compressive, while stresses in the APS Mo-Si-B coatings were tensile. In both cases, residual stresses became more compressive with increasing spray particle velocity due to increased peening imparted by the spray particles. The hardness and elastic moduli of FeAl coatings also increased with increasing particle velocity, again due to an increased peening effect. For Mo-Si-B coatings, plasma spraying at $180 \mathrm{~m} / \mathrm{s}$ resulted in significant oxidation of the spray particles and conversion of the T1 phase into amorphous silica and $\alpha$-Mo. The T1 phase was retained after spraying at $350 \mathrm{~m} / \mathrm{s}$.
\end{abstract}

\section{Introduction}

High-temperature intermetallic compounds are being studied and developed for applications in advanced power plants (coal-fired plants, land-based and aero engine gas turbines) due to their potential high-temperature strength, oxidation resistance, and lowered density relative to conventional Fe- and Ni-based alloys [1-3]. These materials continue to face a number of challenges, however, particularly with regard to obtaining a combination of high-temperature creep strength and low-temperature ductility. Another avenue for the development of these materials is to utilize, where appropriate, their intrinsic high-temperature oxidation resistance through application as coatings on less oxidation-resistant structural materials.

Thermal spray processes such plasma and high-velocity oxy-fuel (HVOF) spraying represent a cost-effective means of the application of intermetallics as coatings. The characteristics of an $\mathrm{Fe}_{3} \mathrm{Al}$-based alloy applied using HVOF spraying have been previously presented [4,5]. The present article describes the processing and characterization of thermal spray coatings based on $\mathrm{FeAl}$ and boron-modified $\mathrm{Mo}_{5} \mathrm{Si}_{3}$ intermetallic compounds. As with $\mathrm{Fe}_{3} \mathrm{Al}$, these compounds are of interest due to their resistance to high-temperature environmental attack.

The advantage of boron-modified $\mathrm{Mo}_{5} \mathrm{Si}_{3}$ over the iron aluminides is its excellent oxidation resistance at temperatures above $800^{\circ} \mathrm{C}$ resulting from the formation of a protective $\mathrm{SiO}_{2}$ layer [6,7]. The addition of $\mathrm{B}$ lowers the viscosity of the $\mathrm{SiO}_{2} \mathrm{scale}$, permitting sintering of the scale to close pores. It is, however, subject to "pesting" attack (formation and evaporation of $\mathrm{MoO}_{3}$ ) at lower temperatures. Boron-modified $\mathrm{Mo}_{5} \mathrm{Si}_{3}$ may hold promise as an oxidation resistant coating on refractory metals operating at temperatures greater than $1000^{\circ} \mathrm{C}$.

The use of plasma spray deposition as a means of fabricating Mo-Si-B composites has been previously reported [8,9]. Kramer, et al [8] formed Mo-Si-B deposits using standard plasma spray techniques in air and low-pressure Ar. Due to significant oxygen pickup during air spraying, spraying in inert gas was recommended for production of monolithic forms using plasma spray. The as-sprayed microstructures showed significant cracking and debonding, but annealing at $1800^{\circ} \mathrm{C}$ for two hours eliminated the cracking and increased the density (from $\sim 90 \%$ theoretical to $\sim 95 \%$ ). In a second paper, Kramer, et al. [10] also report the initial preparation of $\sim 500 \mu \mathrm{m}$ thick Mo-Si-B coatings by plasma spraying in reduced Ar pressure. The amount of porosity in the coatings varied markedly with feedstock powder particle size; finer powder produced denser coatings. 
This paper reports on the preparation of $\mathrm{FeAl}$ and boron-modified $\mathrm{Mo}_{5} \mathrm{Si}_{3}$ coatings using HVOF and air plasma spray (APS) processes, respectively. Coatings were sprayed onto low-carbon and stainless steel substrates. As in the previous work [4,5], coatings were prepared using a range of spray particle velocities, and the effects of particle velocity on the coating characteristics were assessed. The coatings were characterized in terms of microstructure, residual stress, microhardness, elastic modulus, and thermal expansion.

\section{Procedures}

Gas-atomized FeAl powder with a nominal composition of Fe-24.1Al-0.5Mo-0.1Zr (wt.\%) was obtained from Ametek Specialty Metal Products Division. The size distribution was such that essentially all of the particles were less than $38 \mu \mathrm{m}$ in diameter (270 mesh). FeAl coatings were prepared by HVOF thermal spraying in air using a Hobart-Tafia Technologies JP-5000 system. Coatings were produced at an equivalence ratio of one (a stoichiometric mixture of kerosene and oxygen) and three torch chamber gage pressures: 340,520 , and $620 \mathrm{kPa}$. Measurement of the particle temperature and velocity characteristics (using an integrated Doppler velocimeter and high-speed two-color pyrometer) was performed for each gage pressure. As shown in Table 1 , the mean particle velocity increases with increasing chamber pressure while the particle temperature remains essentially constant. Coatings approximately 250 to $1500 \mu \mathrm{m}$ thick were built upon low-carbon and stainless steel substrates in $45 \mu \mathrm{m}$ thick layers in a raster deposition scheme at a standoff distance of $355 \mathrm{~mm}$. A more detailed description of the HVOF coating apparatus is given in Ref. [5].

Mo-Si-B powder with a nominal composition of Mo-13.4Si-2.6B was obtained from Ames Laboratory. Coatings were prepared by plasma spraying in air at atmospheric pressure using a SG100 torch. Particle velocities and temperatures were measured using the same system as described above; the spray parameters and resulting particle characteristics are shown in Table 2 . Coatings $500 \mu \mathrm{m}$ thick were deposited onto thin low-carbon steel substrates at both conditions for curvature-based residual stress measurement and microstructural evaluation. Additional coatings up to $1500 \mu \mathrm{m}$ thick were produced at the higher velocity conditions for further residual stress measurements and free-standing physical property specimens.

Residual stresses in the coatings were characterized by curvature measurements on coating-substrate couples. Average coating and substrate stresses were calculated from the measured curvature using the simple beam bending model described in Ref. [11]. The required physical parameters (elastic modulus)were measured on free-standing coating specimens (described below). As a check on the validity of the curvature based model, residual stresses in the FeAl coatings were directly measured using XRD techniques. Prior to measurement, $100 \mu \mathrm{m}$ was removed from the coating surface by grinding and polishing. Microstructural characterization was performed on transverse coating sections in the as-polished condition using metallography, microhardness measurements, XRD-based dislocation density analysis, and scanning electron microscopy (SEM) coupled with energy-dispersive $\mathrm{X}$-ray spectroscopy (EDS).

The mean coefficient of thermal expansion (CTE) was measured using a dilatometer. Free-standing coating specimens 6.3 mm long were sectioned from $1.5 \mathrm{~mm}$ thick coatings; a Pt standard was used as the reference. Three sequential runs were performed on each specimen to observe changes in expansion behavior with thermal cycling. Elastic modulus measurements were made on free-stranding coatings with strain gages.

\section{Results}

\subsection{Coating Microstructure}

Typical microstructures are shown in Fig. 1 for FeAl coatings prepared at 540 and 660 m/s. All coatings showed B2 ordering in XRD analysis, and no significant differences in chemistry were observed between the coatings and the feedstock powder. As identified in the figure, the coatings exhibited measureable fractions of porosity, oxide inclusions, and unmelted particles. The porosity of coatings sprayed $540 \mathrm{~m} / \mathrm{s}$ was $5-6 \%$; while essentially zero porosity was observed at the higher velocities. Similarly, the fraction of oxide varied from 5-6\% to $1 \%$ with increasing velocity. The coating microhardness increased with spray velocity from $310 \mathrm{DPH}$ at a spray velocity of $540 \mathrm{~m} / \mathrm{s}$ to $580 \mathrm{DPH}$ at a spray velocity of $700 \mathrm{~m} / \mathrm{s}$. The microhardness values translate to yield stresses ranging from approximately 700 to 1,300 MPa. Dislocation densities computed from X-ray peak broadening were essentially constant at $2 \times 10^{11} \mathrm{~cm}^{-2}$. 
Adherent coatings were prepared from the Mo-Si-B powder for all spray conditions investigated. Typical SEM microstructures of coatings produced at low and high spray particle velocities are shown in Fig. 2. The images were taken in BSE imaging mode with high contrast settings to highlight atomic number differences between the constituent phases. Several gradations in darkness corresponding to differing Mo to Si ratios are apparent in both coatings. The primary morphological difference between the two coatings is the presence of a significant quantity of spherical particles in the coating sprayed at lower velocity. Significant cracking of the coating adjacent to the coating-substrate interface was observed for the low-velocity coating. Although the coating microstructures appeared similar when observed in the SEM, XRD analysis of the coatings revealed marked differences. Figure 3 shows XRD scans for coatings prepared at low and high velocities along with that of the starting powder. Analysis of the powder confirms that the original structure is a mixture of $\mathrm{Mo}_{5} \mathrm{Si}_{3}, \mathrm{MoSi}_{2}$, and $\mathrm{MoB}$, whereas after low-velocity plasma spraying, only a single peak corresponding to $\alpha$-Mo is observed. More of the original structure is retained following spraying at the higher particle velocity, although an $\alpha$-Mo peak is present. Both coatings also appear to show a broad hump in the background indicative of an amorphous phase.

Significant chemical changes occurred during the spray process. While EDS analysis showed the atomic ratio of Mo to Si in the starting powder to be approximately 1.9 , this figure increased (due to Si loss) to 2.3 for the high-velocity coating and to 5.7 for the low-velocity coating. The microhardness of the Mo-Si-B coatings was relatively high-the mean value for the low-velocity coating was $640 \mathrm{DPH}$, and the mean value for the high-velocity coating was $600 \mathrm{DPH}$. Microcracking along splat and phase interfaces in the immediate vicinity of the indents was observed, but no cracks emanated from the indent corners.

\subsection{Residual Stress and Physical Properties}

The curvatures of coating-substrate couples, calculated average coating and substrate residual stresses, and XRD-measured coating residual stresses are shown in Tables 3 and 4 for FeAl and Mo-Si-B coatings, respectively. Residual stresses in the FeAl coatings were compressive and increased in magnitude with increasing spray particle velocity. Good agreement was observed between calculated average coating residual stresses and residual stresses measured using XRD on polished coating surfaces. Residual stresses for the plasma-sprayed Mo-Si-B coatings were tensile. The stresses in coatings sprayed at the higher particle velocity were lower than those sprayed at the lower velocity—approximately $50 \mathrm{MPa}$ compared to $200 \mathrm{MPa}$. As with the FeAl coatings, the average coating residual stress was relatively constant with increasing coating thickness, while the magnitude of the average substrate stress increased.

Figure 4 shows mean CTE data for free-standing FeAl coating specimens prepared at each of the three particle velocities. The first and last of three sequential runs on each specimen are shown, along with literature data for wrought $\mathrm{FeAl} \mathrm{[12].} \mathrm{The} \mathrm{data} \mathrm{for}$ the second and third runs were identical. The CTE data for the first coating runs lie below the literature data, while that for the third runs are slightly higher than the literature. There is little difference between coatings prepared at different velocities, except that data for the as-sprayed, $700 \mathrm{~m} / \mathrm{s}$ coating are higher at low temperature than those for lower-velocity coatings. In the first run, the coatings show a drop in mean $\mathrm{CTE}$ at approximately $320^{\circ} \mathrm{C}$, and again at $760^{\circ} \mathrm{C}$. Net shrinkage of the coating specimens was observed after the first run, $\sim 0.5 \%$ for all specimens. No dimensional changes were observed following the second and third runs. Figure 4 also shows mean CTE data for free-standing Mo-Si-B coating specimens prepared at the $350 \mathrm{~m} / \mathrm{s}$ particle velocity. For comparison, average CTE values $(\alpha)$ for $\mathrm{Mo}_{5} \mathrm{Si}_{3}$ and $\mathrm{MoSi}_{2}$ were computed from single crystal data [13] and are included in the figure. As with FeAl coatings, the data from the first CTE run were different than for subsequent runs, and a net shrinkage upon cooling to room temperature of $0.15 \%$ was measured.

The elastic modulus of FeAl coatings sprayed at the two higher particle velocities was higher than that of the lowest, approximately $150 \mathrm{GPa}$ compared to $120 \mathrm{GPa}$. For the Mo-Si-B specimens, the apparent modulus decreased with elastic cycling - from $175 \mathrm{GPa}$ in the first loading to $70 \mathrm{GPa}$ in the third loading.

\section{Discussion}

The results presented demonstrate the successful production of $\mathrm{FeAl}$ and Mo-Si-B coatings using HVOF and APS techniques, respectively. Sound, adherent coatings with minimal porosity and--in the case of FeAl--oxide inclusions were produced in thicknesses up to $1.5 \mathrm{~mm}$. The high particle velocity of HVOF spraying resulted in compressive residual coating stresses for the FeAl coatings, and increasing the plasma spray particle velocity significantly reduced the magnitude of tensile residual stresses for the Mo-Si-B coatings. Discussion of relevant coating issues for each alloy are presented below. 
An effect of HVOF particle velocity on the microstructure and properties of $\mathrm{FeAl}$ coatings was observed. The effects were essentially identical to those previously described for HVOF-sprayed $\mathrm{Fe}_{3} \mathrm{Al}$ coatings [4,5]—increasing particle velocity results in decreased porosity and oxide inclusion levels, increased microhardness, more compressive residual stresses, and increased elastic modulus. These effects all stem from the increased peening effect of higher-velocity particles. It is not currently known why porosity and unmelted particle fractions increase in the FeAl coatings going from $660 \mathrm{~m} / \mathrm{s}$ to $700 \mathrm{~m} / \mathrm{s}$, when these fractions monotonically decrease in $\mathrm{Fe}_{3} \mathrm{Al}$ coatings. Residual stresses in the $\mathrm{FeAl}$ coatings range from just barely compressive (10 to 30 $\mathrm{MPa}$ ) to highly compressive (180 to $200 \mathrm{MPa}$ ). The curvature results are supported by the agreement between the average coating stress calculated from curvature and the XRD-measured stress near the coating surface.

The microstructures of HVOF FeAl coatings reported in [14] are similar to those reported here, although a small fraction of $\mathrm{Fe}_{3} \mathrm{Al}$ was observed in the earlier study. The reported hardness values (290 and 390 DPH) are considerably lower than those observed in the present study. Although no particle velocity or temperature data were presented in Ref. [14], it is likely that the lowered hardness results from a lower spray particle velocity. The coating CTE values are similar to those of wrought FeAl [12]. As previously reported for $\mathrm{HVOF} \mathrm{Fe}_{3} \mathrm{Al}$ coatings, the expansion behavior in the first heating cycle is significantly different than in subsequent cycles. Distinct drops in mean CTE are observed at 320 and $760^{\circ} \mathrm{C}$, and a net shrinkage of $0.5 \%$ is observed after cooling to room temperature. For $\mathrm{Fe}_{3} \mathrm{Al}$ [4], similar drops in CTE (at 400 and $820^{\circ} \mathrm{C}$ ) and net shrinkage were observed. These observations are consistent with recovery and recrystallization of the as-sprayed coating microstructure. The elastic modulus values for the FeAl coatings show good agreement with wrought $\mathrm{FeAl}$ of a similar composition, 150-160 GPa for the coatings compared to $167 \mathrm{GPa}$ for wrought material [12]. The modulus of the coating prepared with a particle velocity of $540 \mathrm{~m} / \mathrm{s}$ was somewhat lower than those at higher velocites, which likely results from porosity present in the low-velocity coating.

The effect of spray particle velocity on APS Mo-Si-B coatings was more marked-microstructure and chemistry were both strongly affected. Spherical droplets associated with poor interparticle bonding and local porosity were present in the lowvelocity coating, while the high-velocity coating exhibited a microstructure of dense, apparently well-bonded lamellar splats. XRD analysis of the low-velocity coating surface indicates the conversion of the powder microstructural constituents to $\alpha$-Mo and amorphous $\mathrm{SiO}_{2}$; the initial constituents were substantially retained in the high-velocity coating, although $\alpha$-Mo is also observed. EDS analysis verifies that the coating sprayed at low velocity lost considerable Si during the spray process (56\% of the original amount), in comparison with the high-velocity coating, for which Si was less reduced (14\%).

These microstructural effects are related to particle oxidation, the extent of which increases with decreased spray particle velocity. This effect is two-fold: lower velocities result in both a longer particle time-of-flight and a higher mean particle temperature. Hence both the oxidation time and temperature are affected. Higher particle temperatures at slower velocity result from an increased residence time in which heat transfer from the plasma to the spray particles occurs. The magnitude of the effect is significant - the mean particle temperature at $180 \mathrm{~m} / \mathrm{s}$ was $2600^{\circ} \mathrm{C}$, versus $2130^{\circ} \mathrm{C}$ for $350 \mathrm{~m} / \mathrm{s}$. In the Mo-Si-B alloy, $\mathrm{Si}$ preferentially oxidizes, forming amorphous $\mathrm{SiO}_{2}$. At the spray temperatures the $\mathrm{SiO}_{2}$ is liquid and will ablate or evaporate from the particles. Hence higher temperature and more time at temperature result in greater Si loss and $\alpha$-Mo formation. The spherical particles observed in the low-velocity coating are believed to be redeposited droplets formed by "splashing" of the spray particles upon surface impact. In contrast, the viscosity of the cooler, higher-velocity particles will be greater, reducing the tendency for splashing. Since the melting point of the T1 phase $\left(2180^{\circ} \mathrm{C}\right)$ is near the mean particle temperature, the highervelocity spray particles may in fact have been semi-solid rather than fully molten.

As with FeAl coatings, increasing spray particle velocity leads to more compressive residual stresses. In the case of plasma spraying, however, the quench component of the residual stress is high due to the larger temperature difference between the spray particle and the substrate $[11,15]$. The net coating residual stress therefore remains tensile, even with relatively high-velocity particles impacting the surface. The difference in residual stress between the coatings prepared with high- and low-velocity particles indicates that peening effects can play a significant role in plasma spraying.

As observed for $\mathrm{FeAl}$ and $\mathrm{Fe}_{3} \mathrm{Al}$, the $\mathrm{CTE}$ for the first heating cycle of the Mo-Si-B coatings was lower than in subsequent runs, and a small net shrinkage was observed after the first run. As expected, CTE data for the coatings lie between literature data for $\mathrm{Mo}_{5} \mathrm{Si}_{3}$ and $\mathrm{MoSi}_{2}$. The Mo-Si-B coating elastic modulus appeared to decrease in each loading cycle, likely indicating microcracking under load, which is expected given the poor interparticle bonding and the brittle nature of the constituent phases, as seen in the vicinity of hardness indents. Similar dramatic reductions in effective modulus have been observed for plasma- 
sprayed ceramic coatings [15]. In terms of magnitude, the initial coating modulus (175 GPa) was considerably less than literature values reported for $\mathrm{Mo}_{5} \mathrm{Si}_{3}(260 \mathrm{GPa})$ and $\mathrm{MoSi}_{2}(390 \mathrm{GPa})$ [16].

\section{Conclusions}

FeAl and Mo-Si-B coatings were successfully applied onto steel substrates using HVOF and APS spraying in air. Sound, adherent coatings were produced with no or low porosity. For FeAl, higher spray particle velocities resulted in coating microstructures with lower porosity and oxide contents. Residual stresses in FeAl coatings were compressive and increased with increasing spray particle velocity.

For plasma sprayed Mo-Si-B, significant oxidation and Si loss occurred at a low spray particle velocity, resulting in conversion of $\mathrm{T} 1$ phase to $\alpha-\mathrm{Mo}$ and amorphous $\mathrm{SiO}_{2}$. The extent of $\mathrm{Si}$ loss was considerably reduced at a higher spray particle velocity, and the original microstructural constituents were retained. Residual stresses in Mo-Si-B coatings were tensile; the magnitude of the tensile stresses was lower for coatings sprayed at the higher particle velocity. In both alloys the average residual coating stress was independent of coating thickness for coatings greater than $500 \mu \mathrm{m}$ thick.

The mean CTE of the coatings was lower in the as-sprayed condition than in an annealed condition; this reduction is attributed to recovery and recrystallization of the heavily cold-worked initial coating microstructure. CTE values in the annealed condition are similar to those of wrought alloys.

\section{Acknowledgements}

The authors would like to acknowledge the assistance of D.C. Haggard with preparation of coatings and T.C. Morris with metallography. This work was supported by the U.S. Department of Energy, Office of Fossil Energy, under DOE Idaho Operations Office contract DE-AC07-99ID13727.

\section{References}

1. Deevi SC, Sikka VK. Intermetallics 1996;4:357.

2. Akinc M, Meyer MK, Kramer MJ, Thom AJ, Huebsch JJ, Cook BA. Mater Sci Eng A 1999;A261:16.

3. Stoloff NS. Mater Sci Eng A 1998;A258:1.

4. Totemeier TC, Wright RN, Swank WD. Metall Mater Trans A 2003, in press.

5. Totemeier TC, Wright RN, Swank WD. J Therm Spray Technol 2002;11:400.

6. Meyer MK, Akinc M. J Am Ceram Soc 1996;79:2763.

7. Thom AJ, Summers E, Akinc M. Intermetallics 2002;10:555.

8. Kramer M, Okumus SC, Besser MF, Unal O, Akinc M. J Therm Spray Technol 2000;9:90.

9. Fan X, Ishigaki T. J Therm Spray Technol 2001;10:611.

10. Kramer M, Degirmen O, Thom AJ, Akinc M. In: Judkins RR, editor. 15th Annual Conference on Fossil Energy Materials. Knoxville, TN: Oak Ridge National Laboratory, 2001.

11. Clyne TW, Gill SC. J Therm Spray Technol 1996;5:401.

12. Schneibel JH. In: Schneibel JH et al, editor. Processing, Properties, and Applications of Iron Aluminides. Warrendale, PA: TMS, 1994. p. 329. 
13. Chu F, Thoma DJ, McClellan K, Peralta P, He Y. Intermetallics 1999;7:611.

14. Grosdidier T, Liao HL, Tidu A. In: Berndt CC, editor. Thermal Spray: Surface Engineering via Applied Research. Materials Park, OH: ASM International, 2000. p. 1341.

15. Gill SC, Clyne TW. Metall Trans B 1990;21B:377.

16. Srinivasan SR, Schwartz RB. J Mater Res 1992;7:1610.

Table 1: Particle temperatures and velocities for HVOF spraying

\begin{tabular}{cccc}
\hline $\begin{array}{c}\text { Chamber Pressure } \\
(\mathrm{kPa})\end{array}$ & $\begin{array}{c}\text { Equivalence Ratio } \\
350\end{array}$ & $\begin{array}{c}\text { Mean Particle Velocity } \\
(\mathrm{m} / \mathrm{s})\end{array}$ & $\begin{array}{c}\text { Mean Particle } \\
\text { Temperature }\left({ }^{\circ} \mathrm{C}\right)\end{array}$ \\
\hline 520 & 1.0 & 540 & 1320 \\
650 & 1.0 & 660 & 1345 \\
\end{tabular}

Table 2: Particle temperatures and velocities for air plasma spraying

\begin{tabular}{lllllll}
\hline Condition & Anode & $\begin{array}{l}\text { Current } \\
\text { (A) }\end{array}$ & $\begin{array}{l}\text { Primary Gas } \\
\text { Flow: } \\
\mathrm{Ar}\left(\mathrm{slm}^{\mathrm{a}}\right)\end{array}$ & $\begin{array}{l}\text { Secondary } \\
\text { Gas Flow: } \\
\text { He }(\mathrm{slm})\end{array}$ & $\begin{array}{l}\text { Mean Particle } \\
\text { Velocity } \\
(\mathrm{m} / \mathrm{s})\end{array}$ & $\begin{array}{c}\text { Mean Particle } \\
\text { Temperature } \\
\left({ }^{\circ} \mathrm{C}\right)\end{array}$ \\
\hline $\begin{array}{l}\text { Low- } \\
\text { velocity } \\
\begin{array}{l}\text { High- } \\
\text { velocity }\end{array}\end{array}$ & Mach II & 800 & 80 & 10 & 180 & 2600 \\
\hline
\end{tabular}

Table 3: Residual stresses for FeAl coatings applied to carbon steel substrates

\begin{tabular}{|c|c|c|c|c|c|}
\hline $\begin{array}{c}\text { Spray Particle } \\
\text { Velocity } \\
(\mathrm{m} / \mathrm{s})\end{array}$ & $\begin{array}{c}\text { Coating } \\
\text { Thickness } \\
(\mu \mathrm{m})\end{array}$ & $\begin{array}{l}\text { Curvature } \\
\left(\mathrm{m}^{-1}\right) \\
\end{array}$ & $\begin{array}{c}\text { Average } \\
\text { Coating Stress } \\
(\mathrm{MPa})\end{array}$ & $\begin{array}{c}\text { Average } \\
\text { Substrate Stress } \\
(\mathrm{MPa})\end{array}$ & $\begin{array}{c}\text { XRD } \\
\text { Coating Stress } \\
(\mathrm{MPa}) \\
\end{array}$ \\
\hline 540 & 260 & 0.023 & -10 & 0 & \\
\hline 540 & 480 & 0.082 & -10 & 0 & \\
\hline 540 & 690 & 0.102 & -10 & +10 & \\
\hline 540 & 910 & 0.225 & -10 & +10 & \\
\hline 540 & 1130 & 0.488 & -30 & +30 & -40 \\
\hline 660 & 340 & 0.206 & -40 & +10 & \\
\hline 660 & 470 & 0.716 & -120 & +40 & \\
\hline 660 & 770 & 1.147 & -90 & +50 & \\
\hline 660 & 1030 & 1.447 & -90 & +70 & \\
\hline 660 & 1250 & 1.835 & -110 & +100 & -100 \\
\hline 700 & 260 & 0.415 & -130 & +20 & \\
\hline 700 & 490 & 1.389 & -200 & +70 & \\
\hline 700 & 700 & 1.647 & -190 & +90 & \\
\hline 700 & 970 & 2.513 & -180 & +130 & \\
\hline 700 & 1270 & 3.096 & -180 & +170 & -150 \\
\hline
\end{tabular}

Table 4: Residual stresses for Mo-Si-B coatings applied to carbon steel substrates 


\begin{tabular}{|c|c|c|c|c|}
\hline $\begin{array}{l}\text { Spray Particle } \\
\text { Velocity } \\
(\mathrm{m} / \mathrm{s})\end{array}$ & $\begin{array}{c}\text { Coating } \\
\text { Thickness } \\
(\mu \mathrm{m})\end{array}$ & Curvature & $\begin{array}{c}\text { Average } \\
\text { Coating Stress } \\
\text { (MPa) }\end{array}$ & $\begin{array}{c}\text { Average } \\
\text { Substrate Stress } \\
(\mathrm{MPa})\end{array}$ \\
\hline 180 & 530 & -1.515 & +210 & -80 \\
\hline 350 & 190 & -0.232 & +102 & -10 \\
\hline 350 & 460 & -0.107 & +20 & -10 \\
\hline 350 & 800 & -0.318 & +30 & -20 \\
\hline 350 & 1000 & -0.799 & +60 & -40 \\
\hline 350 & 1200 & -0.794 & +50 & -50 \\
\hline
\end{tabular}

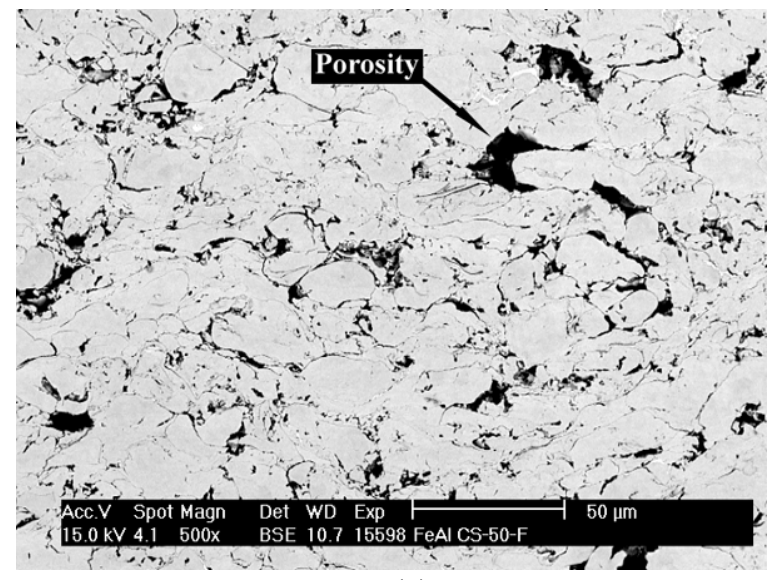

(a)

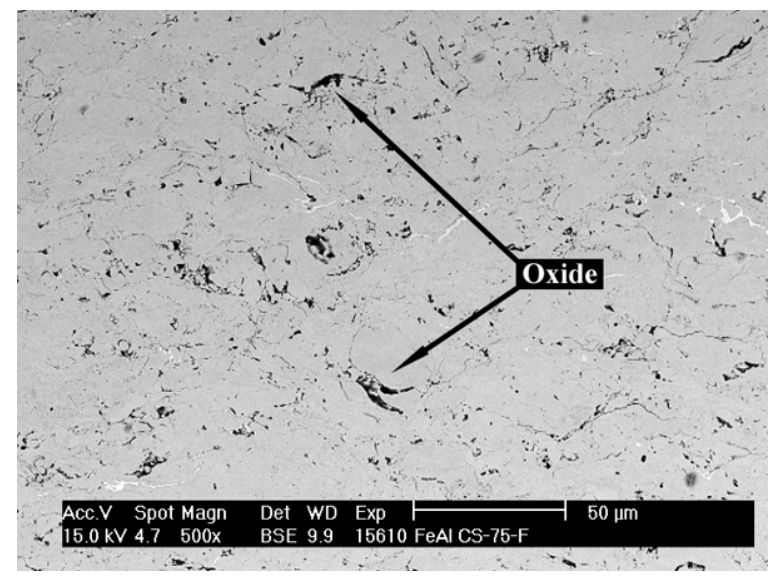

(b)

Figure 1: Typical microstructures of FeAl coatings HVOF sprayed at (a) $530 \mathrm{~m} / \mathrm{s}$ and (b) $660 \mathrm{~m} / \mathrm{s}$ particle velocities.

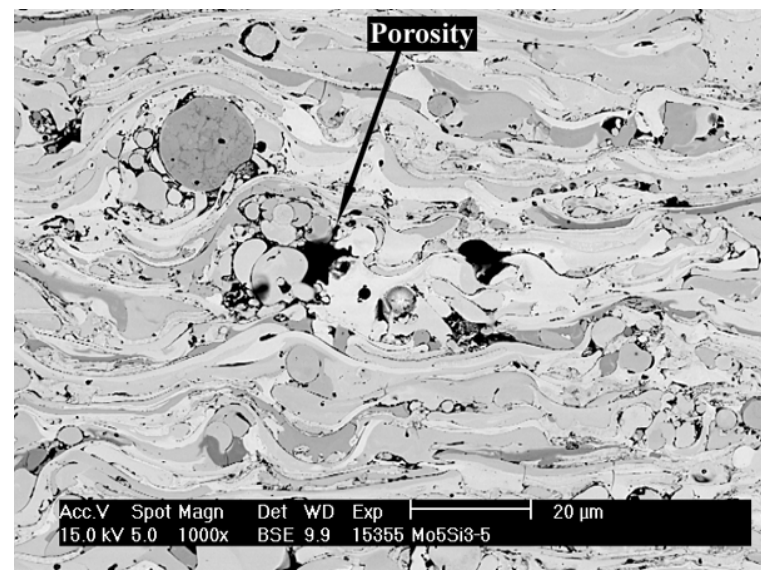

(a)

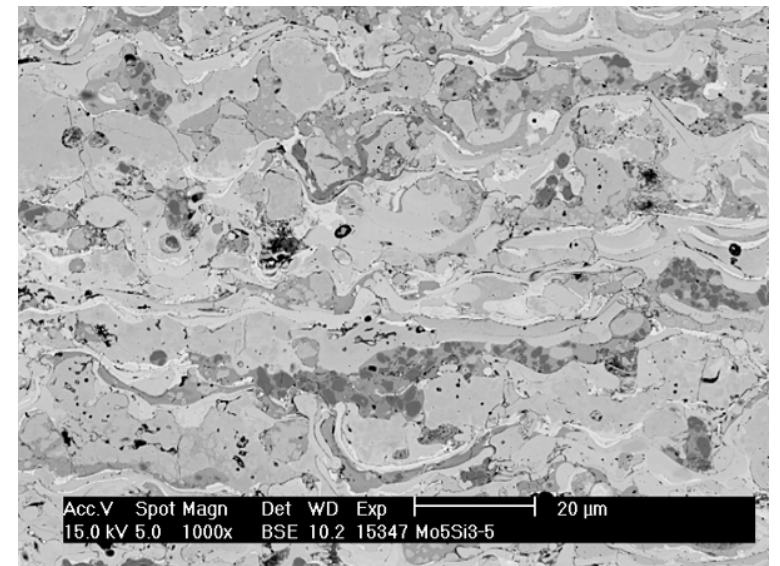

(b)

Figure 2: Typical microstructures of Mo-Si-B coatings APS sprayed at (a) $180 \mathrm{~m} / \mathrm{s}$ and (b) $350 \mathrm{~m} / \mathrm{s}$ particle velocities. 


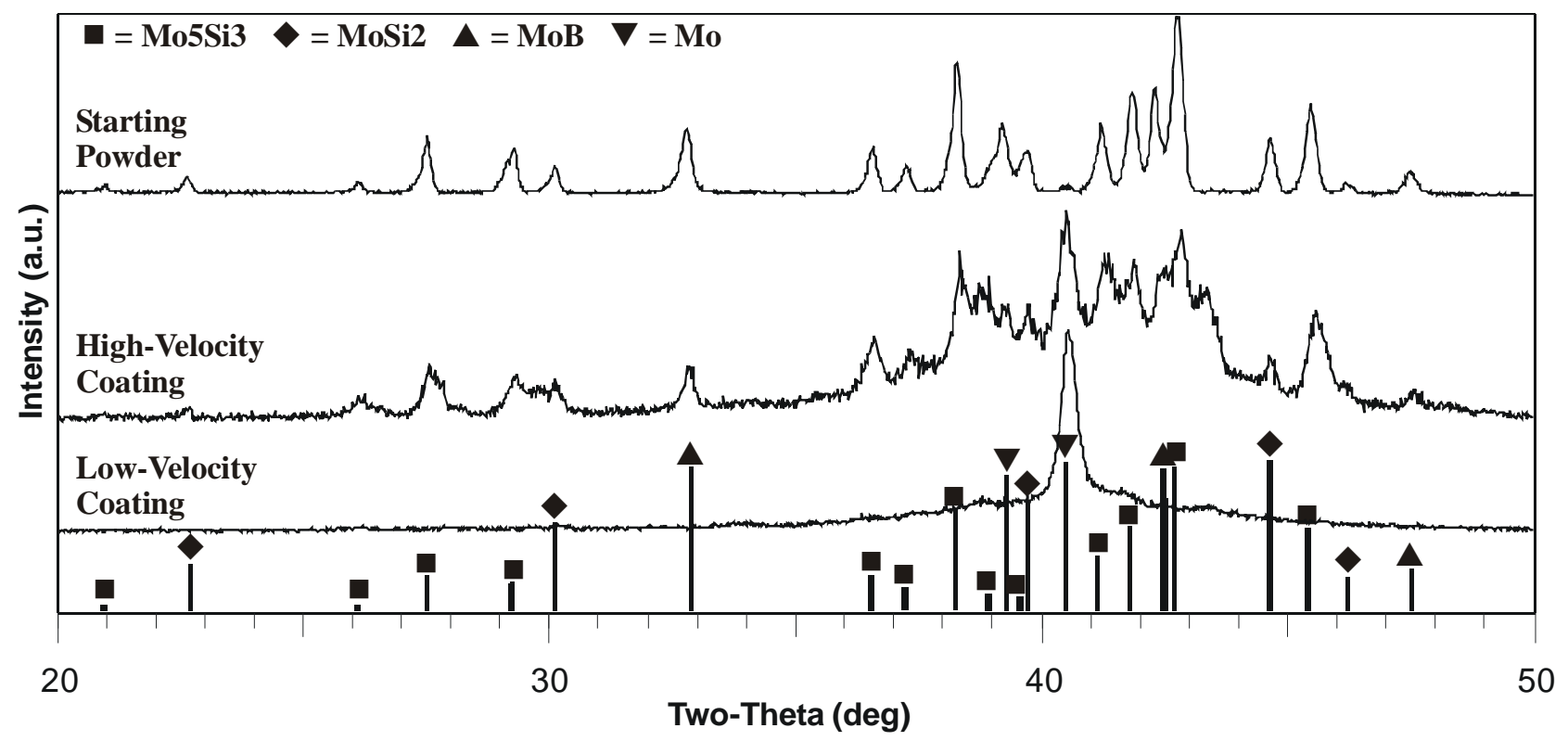

Figure 3: XRD scans of Mo-Si-B feedstock powder and APS coatings sprayed at velocities of $180 \mathrm{~m} / \mathrm{s}$ (low velocity) and $350 \mathrm{~m} / \mathrm{s}$ (high velocity).

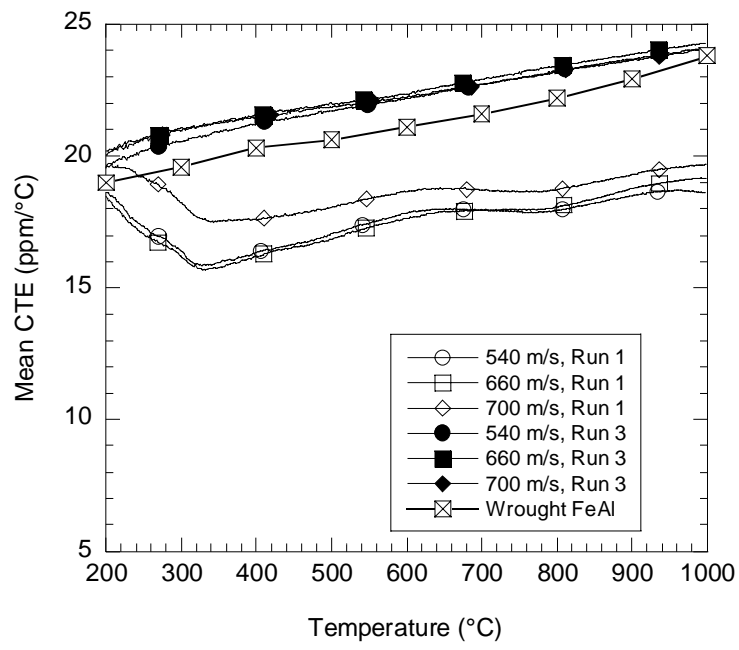

(a)

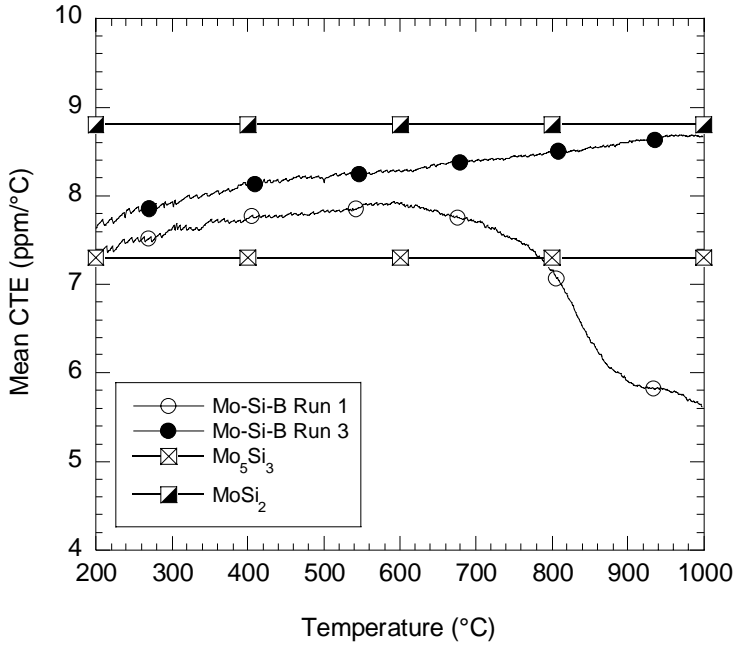

(b)

Figure 4: Mean CTE data for (a) FeAl coatings HVOF sprayed at varying particle velocities, and (b) a Mo-Si-B coating sprayed at $350 \mathrm{~m} / \mathrm{s}$. 